\title{
Comparative Study of Inhibitory Potential of Dietary Phytochemicals Against Quorum Sensing Activity of and Biofilm Formation by Chromobacterium violaceum 12472, and Swimming and Swarming Behaviour of Pseudomonas aeruginosa PAO1
}

\author{
Elif Burcu Bali*®${ }^{*}$, \\ Kübra Erkan Türkmen ${ }^{2,3}{ }^{\infty}$, \\ Demet Erdönmet $t \odot$ and \\ Necdet Sağlam ${ }^{5} \odot$
}

'Gazi University, Vocational Schoo of Health Services, Department of Medical Services and Techniques, Programme of Medical Laboratory Techniques, 06830 Gölbaşı, Ankara, Turkey

2Karamanoğlu Mehmetbey University, Faculty of Science Department of Biology, 70100 Karaman, Turkey ${ }^{3}$ Hacettepe University, Faculty of Science Department of Biology and Biotechnology, 06800 Beytepe, Ankara, Turkey

${ }^{4}$ Aksaray University, Faculty of Science and Letters, Department of Biology, 68100 Aksaray, Turkey

${ }^{5}$ Hacettepe University, Graduate School of Science and Engineering, Nanotechnology and Nanomedicine Division, 06800 Beytepe, Ankara, Turkey

Received: 27 April 2018 Accepted: 8 February 2019

\section{SUMMARY}

Quorum sensing (QS) and biofilm formation are important mechanisms related to antibiotic resistance of many pathogens. Alternative treatments are needed to prevent recurrent or chronic infections caused by multi-resistant pathogens. Therefore, the aim of this study is to investigate and compare the inhibitory potential of the dietary phytochemicals: curcumin, quercetin, apigenin, pyrogallol, gallic acid and luteolin against QS of and biofilm formation by Chromobacterium violaceum ATCC 12472 and the swimming and swarming abilities of Pseudomonas aeruginosa PAO1. Anti-QS potential of the phytochemicals was evaluated qualitatively and quantitatively using $C$. violaceum via the disk diffusion assay based on violacein pigment inhibition at the subminimal inhibitory concentrations ranging from 46.87 to $750 \mu \mathrm{g} / \mathrm{mL}$. The results of anti-QS and antibiofilm activities on C. violaceum demonstrated that all the phytochemicals except pyrogallol and gallic acid inhibited violacein production (from $(11.0 \pm 0.1)$ to $(88.2 \pm 0.1) \%$ ) in a concentration-dependent manner. In addition, the biofilm formation was also significantly inhibited $(p<0.05)$ in the presence of all the phytochemicals $((1.38 \pm 0.08)-(84.2 \pm 0.2) \%)$. In the present study, the results revealed that quercetin, curcumin, apigenin and luteolin could be promising QS and biofilm inhibitory agents against the C. violaceum 12472 biosensor system. Our findings also suggest that all the phytochemicals, especially curcumin, quercetin and pyrogallol, might be anti-pathogenic agents against $P$. aeruginos $A$ PAO1 infections due to the ability to control QS. However, more comprehensive studies at the molecular level, explaining their anti-QS mechanisms, need to be conducted to confirm these results and identify the genes involved.

Key words: phytochemicals, anti-quorum sensing, Chromobacterium violaceum ATCC 12472, Pseudomonas aeruginosa PAO1, antibiofilm activity

\section{INTRODUCTION}

Chromobacterium violaceum obtained from water, soil, and human skin is a facultative anaerobic, Gram-negative opportunist, which often produces violacein, a characteristic purple, water-insoluble pigment with antibacterial activity. It causes severe morbidity and mortality associated with infections such as bacteremia and abscesses. It is also resistant to multiple antimicrobials, thereby causing recurrent infections (1-3). The production of the violacein pigment in C. violaceum is controlled by quorum sensing (QS), a process of bacterial cell-cell communication in which cells regulate the transcription of the specific genes responsible for the production of antibiotics, biofilm differentiation, cell division, bioluminescence and other processes $(4,5)$.

The QS systems of Gram-negative bacteria are composed of Luxl-type autoinducer synthases that synthesize specific acylated homoserine lactone (AHL) autoinducers and the AHL binds specifically to LuxR receptor protein to trigger specific gene expressions (6). For example, C. violaceum ATCC 12472 produces and responds to cognate autoinducer molecules 
C6-AHL and C4-AHL to induce the production of the violacein pigment (7). The compounds preventing the violacein production by this pathogen, without any bacterial inhibition, could be promising QS inhibitors, capable of attenuating bacterial pathogenicity with a lower risk of resistance development than in the case of antibiotics (8). On the other hand, Pseudomonas aeruginosa is the most prevalent and important opportunistic human pathogen, causing for example fatal lung disease in patients with cystic fibrosis. It can display virulence partially owing to its motility, which plays a significant role in its colonization in various environments, the attachment of the bacteria to surfaces, and biofilm formation. Moreover, the bacterium uses different types of QS signal molecules to synchronize particular gene expressions, including those involved in its biofilm formation and virulence (9-11).

The overuse of conventional antibiotics has resulted in the emergence of diseases caused by multi-resistant bacteria. The disadvantages of conventional antimicrobials include their natural selective pressure and failure to treat infections caused by bacterial biofilms (12). Compared to conventional antimicrobials, plant-derived compounds, especially bioactive phytochemicals, are not generally associated with many side effects, and they have a significant anti-infective potential against infectious diseases (13). Therefore, many bioactive compounds in the form of plant phenols have been used extensively as antimicrobials for decades in traditional medicine (14). In addition, the inhibition of bacterial QS system is being evaluated as a new target for developing anti-infective therapies since blocking of QS would weaken virulence of the pathogens, making them more susceptible to treatment and facilitating easy clearance by host defence mechanisms (15). Therefore, research focused on the discovery of novel phytochemicals and plant extracts specifically targeting QS signalling systems and their biofilm inhibition has increased recently (14-17). Apart from the development of potent therapeutics, the detection of anti-pathogenic phytochemicals interfering with $\mathrm{QS}$ and virulence factor production may reveal promising anti-infective compounds. Hence, the aim of the present study is to comparatively investigate anti-QS and antibiofilm potential of the dietary phytochemicals quercetin, curcumin, apigenin, pyrogallol, gallic acid and luteolin, against C. violaceum ATCC 12472 as well as their inhibitory activities against swimming and swarming abilities of $P$. aeruginosa PAO1. A few of the phytochemicals, particularly quercetin and curcumin, have already been reported to act as anti-QS and antibiofilm agents $(6,18-21)$; however, this study is the first one to compare their inhibitory effects on QS and biofilm formation by C. violaceum 12472, and swimming and swarming motility of $P$. aeruginosa PAO1.

\section{MATERIALS AND METHODS}

\section{Bacterial strains and culture conditions}

In this study, the wild-type strain Chromobacterium violaceum ATCC 12472 and Pseudomonas aeruginosa PAO1 were used as biosensor strains for quorum sensing (QS) and motility assays, respectively. C. violaceum 12472 was a kind gift from Prof. Dr Robert J.C. McLean (University of Texas, TX, USA), and P. aeruginosa PAO1 was also a kind gift from Daniel Lopez, PhD (National Centre for Biotechnology (CNB), Autonomous University of Madrid, Madrid, Spain). The strains were routinely grown in Luria-Bertani (LB) broth (1 \% tryptone, $0.5 \%$ yeast extract and $1 \% \mathrm{NaCl}$ (Sigma-Aldrich, Merck, St. Louis, MO, USA) medium; $\mathrm{pH}=7.0$ ). Flasks with $C$. violaceum and $P$. aeruginosa $\mathrm{PAO} 1$ were incubated at 30 and $37^{\circ} \mathrm{C}$ for $24 \mathrm{~h}$, respectively.

\section{Preparation of dietary phytochemicals}

The dietary phytochemicals (quercetin, curcumin, apigenin, pyrogallol and luteolin) were purchased from Sigma-Aldrich, Merck. Gallic acid and all solvents were from Merck (Darmstadt, Germany). The stock solutions of apigenin and luteolin were prepared in $10 \%$ dymethylsulphoxide (DMSO), those of curcumin and quercetin in $50 \%$ methanol, and pyrogallol and gallic acid were dissolved in distilled water. The final volume fraction of DMSO or methanol was adjusted to $\leq 0.5 \%$, which did not have any discernible effect on the growth of $C$. violaceum 12472. The stock solutions were prepared daily and diluted to the desired volume fraction immediately prior to use. The control groups were $0.5 \%$ DMSO, $0.5 \%$ methanol and the bacteria cultured in LB broth.

\section{Determination of minimum inhibitory concentrations}

Minimum inhibitory concentration (MIC) values of the dietary phytochemicals were determined by the broth microdilution test in 96-well plates as previously described (22) with some modifications. A volume of $100 \mu \mathrm{L}$ of the stock solutions of the phytochemicals ( $50 \% \mathrm{~V} / \mathrm{V}$ ) was added to an equal volume of LB broth, and twofold serial dilutions (1500, 750, 375, 187.5, 93.75 and $46.87 \mu \mathrm{g} / \mathrm{mL}$ ) were prepared in the microtiter plate. Overnight cultures of $C$. violaceum 12472 and $P$. aeruginosa PAO1 were adjusted to the absorbance value $A_{600 \mathrm{~nm}}=0.4$ using sterile broth, and $100 \mu \mathrm{L}$ of each culture were added to the plates, after which the plates were incubated at 30 and $37^{\circ} \mathrm{C}$ for $24 \mathrm{~h}$, respectively. Inhibition of the bacterial growth in the wells containing the phytochemicals was assessed by a comparison with the growth in blank control wells. Every experiment included negative (medium, $0.5 \%$ DMSO, and $0.5 \%$ methanol) and positive control (medium including the inoculum). The MIC was recorded as the lowest concentration at which there was no visible growth of the bacteria. The MIC assay was repeated at least twice. The subminimal inhibitory concentrations (sub-MICs) of each phytochemical $(46.87-750 \mu \mathrm{g} / \mathrm{mL})$ were tested for the assessment of anti-QS and antibiofilm activity.

\section{Quorum sensing inhibition}

\section{Qualitative anti-QS activity: Disc diffusion method}

The standard disc diffusion assay, with few modifications, was used for the detection of the anti-QS potential of the 
dietary phytochemicals using the wild-type pigmented biosensor strain C. violaceum 12472 (23). It was grown in LB broth or on the LB agar $(1.2 \% \mathrm{~m} / \mathrm{V})$. A volume of $5 \mathrm{~mL}$ of molten LB $\operatorname{agar}(0.3 \% \mathrm{~m} / \mathrm{V})$ was inoculated with $50 \mu \mathrm{L}$ of the $C$. violaceum 12472 culture grown overnight in LB broth. The agar solution with the culture was immediately poured over the surface of LB agar plates. A volume of $20 \mu \mathrm{L}$ of each phytochemical solution $(46.87,93.75,187.5,375$ and $750 \mu \mathrm{g} / \mathrm{mL})$ was pipetted on sterile paper disks ( $6 \mathrm{~mm}$ diameter; Bioanalyse ${ }^{\circledR}$, Ankara, Turkey), which was placed on the solidified agar. The plates were incubated overnight at $30^{\circ} \mathrm{C}$ and examined for violacein pigment production. QS inhibition, in sub-MIC values, was detected by a ring of colourless but viable cells around the disks. The measurements were made from the outer edge of the disks to the edge of the zones suggesting anti-QS inhibition. Controls were $0.5 \%$ DMSO and $0.5 \%$ methanol. This experiment was carried out at least three times.

\section{Quantitative anti-QS activity: Violacein inhibition}

Inhibitory potential of the dietary phytochemicals on the violacein pigment production was also measured spectrophotometrically using the method of Blosser and Gray (24), with a few modifications. Quantitative evaluation of anti-QS activity of the phytochemicals was carried out based on their ability to inhibit the production of the purple pigment violacein by C. violaceum 12472. Briefly, the phytochemicals were added to $200 \mu \mathrm{L}$ of bacterial culture (in LB broth) at the sub-MIC concentrations (46.87, 93.75, 187.5, 375 and $750 \mu \mathrm{g} /$ $\mathrm{mL}$ ) and incubated at $30^{\circ} \mathrm{C}$ until complete pigmentation was achieved in the blank, i.e. untreated culture. First, $200 \mu \mathrm{L}$ of treated and untreated cultures were placed in an Eppendorf tube and lysed by addition of $200 \mu \mathrm{L}$ of $10 \%$ SDS, vortexed for $5 \mathrm{~s}$ and incubated at room temperature for $5 \mathrm{~min}$. Subsequently, $900 \mu \mathrm{L}$ of water-saturated butanol $(50 \mathrm{~mL} n$-butanol mixed with $10 \mathrm{~mL}$ distilled water) were added to the cell lysate, followed by vortexing for $5 \mathrm{~s}$ and centrifugation at $13000 \times g$ for $5 \mathrm{~min}$. The upper (butanol) phase containing the violacein was collected and the absorbance was read at 585 $\mathrm{nm}$ in UV-Vis spectrophotometer (UV-1800; Shimadzu, Kyoto, Japan). The percentage of violacein inhibition was calculated using the following formula:

Inhibition $=\left(A_{585 \mathrm{~nm}}(\right.$ control $)-A_{585 \mathrm{~nm}}($ test $) / A_{585 \mathrm{~nm}}($ control $\left.)\right) \cdot 100 / 1 /$

where $A$ is the absorbance, controls were $0.5 \%$ DMSO, $0.5 \%$ methanol and the untreated bacteria, and the test was the culture treated with the phytochemicals. The experiments were performed at least in triplicate.

\section{Antibiofilm activity}

Biofilm formation in 96-well U-bottom polystyrene microtiter plates (Nunc ${ }^{\mathrm{T} M}$, Thermo Fisher Scientific, Waltham, MA, USA) was assayed via a previously described, slightly modified method (25). An overnight culture of $C$. violaceum 12472 was diluted 1:100 with LB broth and grown for another hour. After the addition of sub-MICs of the phytochemicals (46.87, 93.75, 187.5, 375 and $750 \mu \mathrm{g} / \mathrm{mL}$ ), $100 \mu \mathrm{L}$ of the culture were pipetted into the wells of the microtiter plates and the plates were incubated for $24 \mathrm{~h}$ at $30^{\circ} \mathrm{C}$. Then, the medium was removed and washed with $1 \times$ PBS buffer three times. The plates were dried at $65^{\circ} \mathrm{C}$ in a universal oven (UNB 100; Memmert ${ }^{\circledR}$, Schwabach, Germany) and then $100 \mu \mathrm{L}$ of a $1 \% \mathrm{~m} / V$ aqueous solution of crystal violet were added. The stain was allowed to fix at room temperature for $20 \mathrm{~min}$, after which the dye was removed from the wells by washing thoroughly with sterile water. For the quantification of the attached biomass, the bound dye was dissolved with $30 \%$ acetic acid solution, and the absorbance was determined at $595 \mathrm{~nm}$. Inhibitor-mediated reduction of biofilm formation was assessed by comparing it to the positive control without phytochemicals. The biofilm assay was performed three times, and six wells per treatment were used each time.

\section{Swimming and swarming assays}

The swimming and swarming motility assays were performed using a previously described, slightly modified method (26). In swimming assay, $5 \mu \mathrm{L}$ of overnight culture of the Pseudomonas aeruginosa PAO1 $\left(A_{600 \mathrm{~nm}}=0.4\right)$ were point inoculated at the centre of an agar medium consisting of $1 \%$ tryptone, $0.5 \% \mathrm{NaCl}$ and $0.3 \%$ agar with the sub-MIC concentration of the phytochemicals $(93.75 \mu \mathrm{g} / \mathrm{mL})$. For swarming assays, the agar medium comprised $1 \%$ peptone, $0.5 \%$ $\mathrm{NaCl}, 0.5 \%$ agar and $0.5 \%$ filter-sterilized D-glucose with the same sub-MIC concentration of phytochemicals $(93.75 \mu \mathrm{g} / \mathrm{mL})$. The plates were then incubated at $37^{\circ} \mathrm{C}$ in an upright position for $16 \mathrm{~h}$. The reduction in swimming and swarming migration was recorded by measuring the swimming and swarming zones of the bacterial cells after $16 \mathrm{~h}$ compared to the negative controls.

\section{Growth curve assay}

To confirm the anti-QS activity of the dietary phytochemicals, the growth curve assay of $C$. violaceum 12472 cultivated in the presence and absence of phytochemicals was performed. Overnight culture of the bacteria $\left(1 \% ; A_{600 \mathrm{~nm}}=0.4\right)$ was inoculated in a $250-\mathrm{mL}$ Erlenmeyer flask containing $50 \mathrm{~mL}$ of LB broth supplemented with the sub-MIC concentrations (375 and $750 \mu \mathrm{g} / \mathrm{mL}$ ) of each phytochemical. The flasks were incubated at $30^{\circ} \mathrm{C}$ and $180 \mathrm{rpm}$ in a rotary shaker (KS300; IKA ${ }^{\circledR}$-Werke GmbH \& Co. KG, Staufen, Germany). The cell density was measured by UV-Vis spectrophotometer (UV-1800; Shimadzu) at 1-hour intervals up to $20 \mathrm{~h}$. The control was the bacteria without the treatment with phytochemicals (19).

\section{Statistical analysis}

The results were analysed using SPSS (Statistical Package for the Social Sciences) v. 20.0 (27) and expressed as mean value \pm standard deviation (S.D.). The differences between the 
control and test samples were analysed using $t$-test and one-way ANOVA. Differences at $\mathrm{p}<0.05$ were considered statistically significant.

\section{RESULTS AND DISCUSSION}

\section{Minimum inhibitory concentration of dietary phytochemicals against test strains}

MIC was determined for each of the dietary phytochemicals at the concentrations ranging from 1500 to $46.87 \mu \mathrm{g} / \mathrm{mL}$ against Chromobacterium violaceum 12472. The MIC value of gallic acid was found to be $\geq 1500 \mu \mathrm{g} / \mathrm{mL}$. This result corroborates well the findings of Borges et al. (12), who reported the MIC value of gallic acid of $>1000 \mu \mathrm{g} / \mathrm{mL}$ for the same strain. The effect of phenolic acids on the physicochemical properties of bacterial cell surface has shown that these compounds, in particular gallic acid, change bacterial hydrophobicity. As known, phenolic acids alter the polar, nonpolar and electron acceptor components of bacterial cells (28).

In addition to these results, the MIC values of curcumin and pyrogallol were found to be $1500 \mu \mathrm{g} / \mathrm{mL}$ and the MIC values of quercetin, luteolin and apigenin were found to be $750 \mu \mathrm{g} / \mathrm{mL}$. Gopu et al. (6) found that the MIC value of quercetin was $120 \mu \mathrm{g} / \mathrm{mL}$ against C. violaceum CV026. This result differs from our data, which may be due to the use of different methods employed to detect the MIC values, variations in the preparation of the solutions of phytochemicals and/or due to the use of different biosensor strains. In our study, we believe that dietary phytochemicals affect bacterial biochemical activities responsible for bacterial growth.

Phytochemicals are known to have strong antimicrobial effects, which mainly cause structural or functional damage to the bacterial cell membrane (29). They could also show different target mechanisms of antimicrobial activity on bacterial cells, such as the degradation of the cell wall, the leakage of the cell contents, the depletion of the proton motive force, or cytoplasmic protein coagulation or inhibition (30). Ohemeng et al. (31) and Mirzoeva et al. (32) reported that quercetin inhibited DNA gyrase and disrupted the bacterial membrane potential. Sorrentino et al. (33) also reported that gallic acid caused irreversible changes in permeability profile, rupture and pore formation of the bacterial cell membranes. In our study, the dietary phytochemicals may use one of the target mechanisms to inhibit the growth of $C$. violaceum 12472.

\section{Determination of anti-QS activity by disc diffusion method}

The production of the purple pigment violacein in C. violaceum is controlled by QS (4). Loss of the violacein is a hallmark of QS inhibition in C. violaceum 12472 by the dietary phytochemicals. The phytochemicals showed promising anti-QS activity, and a white opaque zone of inhibition was observed in the biosensor plate containing the reference strain C. violaceum 12472 (Fig. 1). The sub-MICs of quercetin, luteolin and apigenin were found to be $<750 \mu \mathrm{g} / \mathrm{mL}$, and of curcumin, pyrogallol and gallic acid $<1500 \mu \mathrm{g} / \mathrm{mL}$. The sub-MICs of each tested phytochemical ranged from 46.87 to $750 \mu \mathrm{g} /$ $\mathrm{mL}$. As shown in Table 1, the anti-QS activity was concentration-dependent, showing an increase in the diameter of the QS inhibition zones with increasing concentrations of the phytochemicals $(p<0.05)$. Among all the phytochemicals screened for the QS inhibition, curcumin, quercetin, luteolin and apigenin exhibited the anti-QS activity, but pyrogallol and gallic acid did not. Al-Hussaini and Mahasneh (34) reported the QS inhibition zones for different herbal extracts with diameters $8-10.5,13$ and $18 \mathrm{~mm}$, corresponding

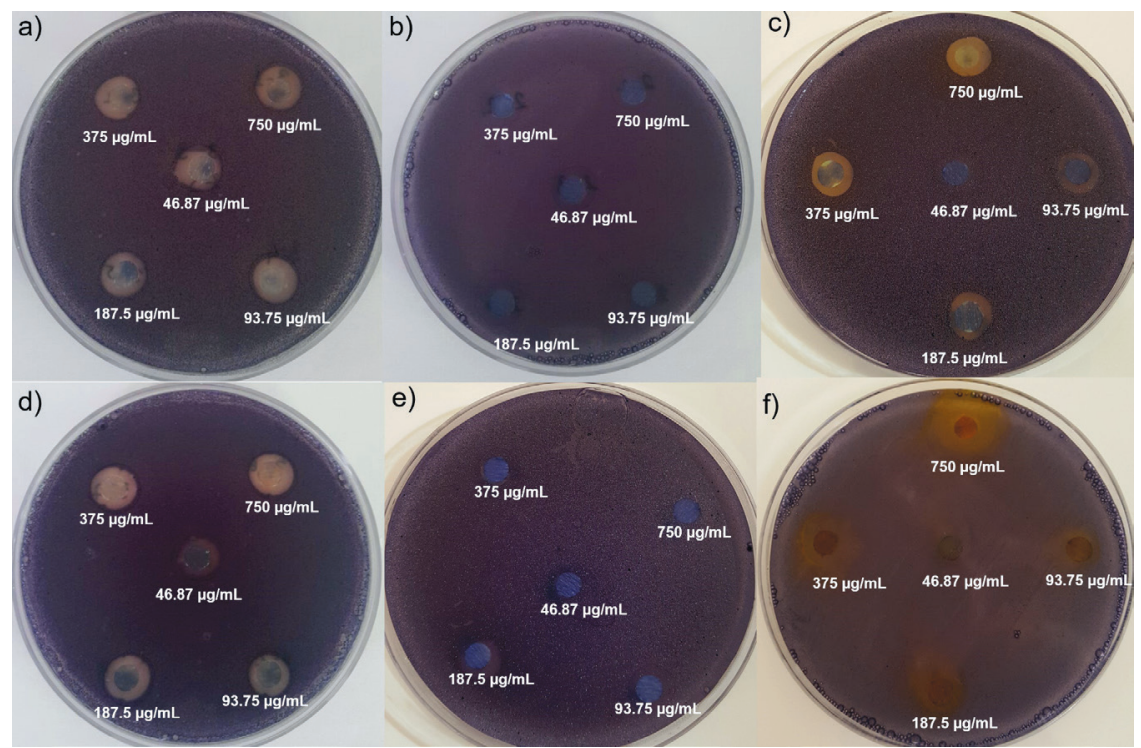

Fig. 1. The anti-quorum sensing activity of the dietary phytochemicals at concentrations from 46.87 to $750 \mu \mathrm{g} / \mathrm{mL}$ against biosensor strain Chromobacterium violaceum ATCC 12472 via disk diffusion method: a) luteolin, b) gallic acid, c) quercetin, d) apigenin, e) pyrogallol, and f) curcumin 
Table 1. Zone of violacein inhibition obtained with the subminimal inhibitory concentrations $(46.87-750 \mu \mathrm{g} / \mathrm{mL})$ of the dietary phytochemicals

\begin{tabular}{ccccccc}
\multirow{2}{*}{$\gamma($ phytochemical $) /(\mu \mathrm{g} / \mathrm{mL})$} & \multicolumn{5}{c}{$d$ (inhibition zone)/mm } \\
\cline { 2 - 7 } 46.87 & CR & QT & PG & GA & LT & AP \\
93.75 & $(7.0 \pm 0.3)^{\mathrm{a}}$ & $(7.5 \pm 0.1)^{\mathrm{a}}$ & NA & NA & $(9.1 \pm 0.1)^{\mathrm{a}}$ & $(9.3 \pm 0.7)^{\mathrm{a}}$ \\
187.5 & $(8.5 \pm 0.0)^{\mathrm{b}}$ & $(8.0 \pm 0.1)^{\mathrm{b}}$ & NA & NA & $(10.1 \pm 0.4)^{\mathrm{b}}$ & $(10.3 \pm 0.7)^{\mathrm{b}}$ \\
375 & $(9.7 \pm 0.1)^{\mathrm{c}}$ & $(9.5 \pm 0.7)^{\mathrm{c}}$ & NA & NA & $(12.3 \pm 0.6)^{\mathrm{c}}$ & $(11.5 \pm 0.5)^{\mathrm{c}}$ \\
750 & $(12.5 \pm 0.3)^{\mathrm{d}}$ & $(12.0 \pm 0.2)^{\mathrm{d}}$ & NA & NA & $(13.6 \pm 0.5)^{\mathrm{d}}$ & $(13.0 \pm 0.1)^{\mathrm{d}}$ \\
& $(13.3 \pm 0.1)^{\mathrm{e}}$ & $(13.3 \pm 0.5)^{\mathrm{e}}$ & NA & NA & $(14.2 \pm 0.1)^{\mathrm{e}}$ & $(14.3 \pm 0.0)^{\mathrm{e}}$ \\
\hline
\end{tabular}

$\mathrm{CR}=$ curcumin, $\mathrm{QT}=$ quercetin, $\mathrm{PG}=$ pyrogallol, $\mathrm{GA}=$ gallic acid, $\mathrm{LT}=$ luteolin, $\mathrm{AP}=$ apigenin; $\mathrm{NA}=$ no activity. The values in the same column with different letters in superscript are significantly different $(p<0.05)$

to weak, moderate and strong anti-QS activity, respectively. In our study, the QS inhibition zones (Table 1) were found for curcumin $((7.0 \pm 0.3)-(13.3 \pm 0.1) \mathrm{mm})$, quercetin $((7.5 \pm 0.1)-$ $(13.3 \pm 0.5) \mathrm{mm})$, luteolin $((9.1 \pm 0.1)-(14.2 \pm 0.1) \mathrm{mm})$ and apigenin $((9.3 \pm 0.7)-(14.3 \pm 0.0) \mathrm{mm})$ at the concentration range of $46.87-750 \mu \mathrm{g} / \mathrm{mL}$. At low concentrations (46.87 and $93.75 \mu \mathrm{g} /$ $\mathrm{mL}$ ), these phytochemicals had weak anti-QS activities. In addition, curcumin $((9.7 \pm 0.1) \mathrm{mm})$ and quercetin $((9.5 \pm 0.7) \mathrm{mm})$ exhibited weaker anti-QS activities than luteolin ((12.3 \pm 0.6$)$ $\mathrm{mm})$ and apigenin $((11.5 \pm 0.5) \mathrm{mm})$ at $187.5 \mu \mathrm{g} / \mathrm{mL}$. However, curcumin $((12.5 \pm 0.3) \mathrm{mm})$, luteolin $((13.6 \pm 0.5) \mathrm{mm})$ and apigenin $((13.0 \pm 0.1) \mathrm{mm})$ showed stronger anti-QS activities than quercetin $((12.0 \pm 0.2) \mathrm{mm})$ at $375 \mu \mathrm{g} / \mathrm{mL}(\mathrm{p}<0.05)$. At the highest sub-MIC $(750 \mu \mathrm{g} / \mathrm{mL})$, curcumin demonstrated the highest QS inhibition (the diameter of zone of inhibition being (13.3 \pm 0.1$) \mathrm{mm}$; Table 1). The concentration-dependent anti-QS activity of the phytochemicals observed in this study is in agreement with some of the findings reported by Borges et al. (12), Husain et al. (15), and Vasavi et al. (20).

\section{Determination of quantitative anti-QS activity by violacein inhibition}

To confirm the QS inhibitory activity of the dietary phytochemicals, the extraction and the quantification of the violacein from C. violaceum 12472 culture was also performed in the presence and absence of the phytochemicals (curcumin, quercetin, pyrogallol, luteolin, gallic acid and apigenin) at the same sub-MIC levels $(46.87-750 \mu \mathrm{g} / \mathrm{mL})$. The results showed a concentration-dependent inhibition of the violacein production by curcumin, quercetin, luteolin and apigenin. Compared to the control, all concentration ranges of curcumin, quercetin, luteolin and apigenin $(46.87-750 \mu \mathrm{g} / \mathrm{mL})$ demonstrated a significant drop in the violacein content of $C$. violaceum 12472, without the inhibition of bacterial growth $(p<0.05)$. As shown in Fig. 2, curcumin, quercetin, luteolin and apigenin inhibited the violacein production $((14.0 \pm 0.3)-(88.2 \pm 0.1) \%$, $(11.1 \pm 0.1)-(55.03 \pm 0.07) \%$, $(37.49 \pm 0.08)-(59.48 \pm 0.08) \%$ and $(36.3 \pm 0.2)-(58.95 \pm 0.08) \%)$ in a concentration-dependent manner. Among all the phytochemicals, curcumin exhibited the most powerful QS inhibitory effect ((54.7 \pm 0.3$),(72.2 \pm 0.2)$ and $(88.2 \pm 0.1) \%)$ at $187.5,375$ and $750 \mu \mathrm{g} / \mathrm{mL}$. At all concentrations, luteolin and apigenin demonstrated stronger violacein inhibition than quercetin (Fig. 2). The results revealed that the percentage of inhibition of QS by apigenin and luteolin was similar at the tested concentrations. This may be because apigenin and luteolin are the flavonoid compounds with similar structures. Thus, the QS inhibitory effect of the phytochemicals was found to be in the following order: curcumin $>$ apigenin $>$ luteolin>quercetin.

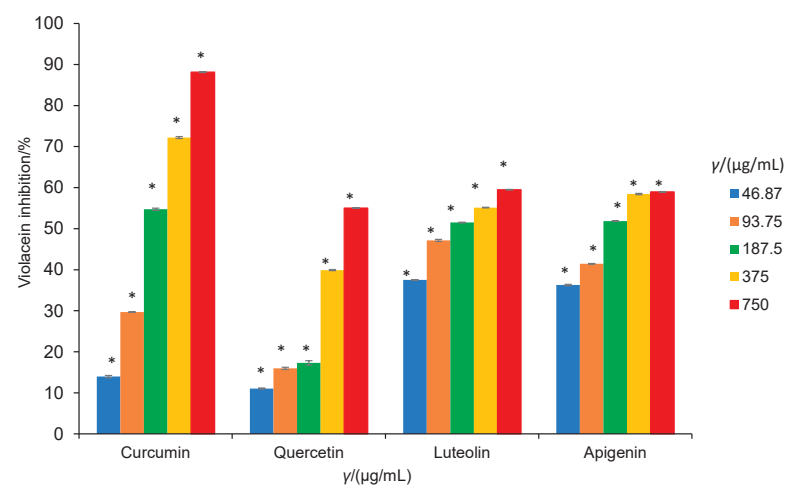

Fig. 2. Quantitative analysis of violacein inhibition in Chromobacterium violaceum ATCC 12472 by the dietary phytochemicals at the subminimal inhibitory concentrations $(46.87-750 \mu \mathrm{g} / \mathrm{mL})$. Data are presented as a percentage of violacein inhibition. Mean values of triplicate independent experiments and S.D. are shown. The control groups were: $0.5 \%$ DMSO, $0.5 \%$ methanol and the bacteria cultured in Luria-Bertani broth. *Statistically different from the control $(p<0.05)$

Brackman et al. (35) found that curcumin inhibited violacein production by $(18 \pm 12) \%$ in C. violaceum CV026 at a concentration of $184 \mu \mathrm{g} / \mathrm{mL}$. In our findings, curcumin inhibited violacein production by $(54.7 \pm 0.3) \%$ at $187.5 \mu \mathrm{g} / \mathrm{mL}$. In addition, in the present study, the violacein inhibition by $750 \mu \mathrm{g} / \mathrm{mL}$ curcumin $((88.2 \pm 0.1) \%)$ is comparable with that of Packiavathy et al. (19), who reported $89 \%$ violacein inhibition in C. violaceum CV026 when treated with $100 \mu \mathrm{g} / \mathrm{mL}$ curcumin. Moreover, the violacein inhibition by quercetin at the maximum sub-MIC of $375 \mu \mathrm{g} / \mathrm{mL}$ ((39.9 \pm 0.1$) \%)$ is comparable with that of Gopu et al. (6), who reported that quercetin exhibited maximum violacein inhibition of $83.23 \%$ in C. violaceum CV026 at a concentration of $80 \mu \mathrm{g} / \mathrm{mL}$. Similarly, $50 \%$ inhibition of the violacein production in C. violaceum 12472 by quercetin $(50 \mu \mathrm{g} / \mathrm{mL})$ was reported by Vasavi et al. (20) using a different method. 
Apigenin and luteolin inhibited violacein ((58.4 \pm 0.2$)$ and (55.13 \pm 0.04$) \%$ ) at $375 \mu \mathrm{g} / \mathrm{mL}$. Vandeputte et al. (36) reported that apigenin and luteolin at the concentration of $4 \mathrm{mM}$ (approx. $1.2 \mathrm{mg} / \mathrm{mL}$ ) exhibit no QS inhibiton, but a bactericidal or bacteriostatic activity on C. violaceum CV026. Our study showed that apigenin and luteolin at the sub-MICs of 375 , $187.5,93.75$ and $46.87 \mu \mathrm{g} / \mathrm{mL}$ showed anti-QS activity on C. violaceum 12472 without inhibition of bacterial growth (Fig. S1, Fig. 1a, Fig. 1d and Fig. 2).

Pyrogallol and gallic acid did not exhibit the anti-QS activity when evaluated by the disk diffusion method. Therefore, the percentage of the violacein inhibition by these phytochemicals was evaluated only at the highest concentration $(1500 \mu \mathrm{g} / \mathrm{mL})$, and the obtained results were $(76.95 \pm 0.02)$ and (58.76 \pm 0.05$) \%$ for pyrogallol and gallic acid respectively (data not shown). Considering that no QS inhibition zones were detected on the agar, these results were observed solely due to the inhibition of bacterial growth since gallic acid and pyrogallol only inhibited microbial growth and not the violacein synthesis. The obtained results are also in agreement with those of Borges et al. (12), who reported that gallic acid exhibited no anti-QS activity on C. violaceum biosensor systems.

Previous research of Borges et al. $(12,37)$ also revealed that as a sustainable source of new broad-spectrum antimicrobial products, gallic acid can cause irreversible changes in some Gram-negative and Gram-positive bacteria. In addition, Tinh et al. (38) reported that pyrogallol also exhibited the antibacterial activity against Vibrio parahaemolyticus. Although pyrogallol is known as the phytochemical with anti-QS activity and the ability to inhibit autoinducer-2 (Al-2)-mediated QS in Vibrio harveyi $(39,40)$, it has been revealed in further investigations that this Al-2-mediated QS inhibition is a side effect of the peroxide-producing activity of this compound rather than true QS inhibition (41). Our findings also show that pyrogallol does not inhibit QS system of the C. violaceum 12472 biosensor strain.

\section{Determination of antibiofilm activity of dietary phytochemicals}

In the present study, the biofilm inhibition potential of all the phytochemicals (curcumin, quercetin, pyrogallol, luteolin, gallic acid and apigenin) was evaluated at the same sub-MIC range (46.87-750 $\mu \mathrm{g} / \mathrm{mL}$ ) (Fig. 3). All the phytochemicals exhibited a significant concentration-dependent antibiofilm activity $(p<0.05)$. Gallic acid showed the weakest biofilm inhibition (from $(1.38 \pm 0.08)$ to $(9.57 \pm 0.06) \%$ ) at $46.87-750 \mu \mathrm{g} /$ $\mathrm{mL}$, although it did not possess antimicrobial activity against C. violaceum 12472 at $<1500 \mu \mathrm{g} / \mathrm{mL}$. Compared to the other compounds (pyrogallol, apigenin, quercetin and luteolin), curcumin showed the weakest biofilm inhibition ((11.0 \pm 0.5$)$ and $(26.7 \pm 0.3) \%$ at 46.87 and $93.75 \mu \mathrm{g} / \mathrm{mL}$, respectively). Our results are comparable with the results of Packiavathy et al. (18), who found that curcumin $(>100 \mu \mathrm{g} / \mathrm{mL})$ inhibited the biofilm formation of Vibrio harveyi (69\%), Vibrio parahaemolyticus (56\%) and Vibrio vulnificus (79\%), without affecting their planktonic growth. Packiavathy et al. (19) also reported that curcumin $(100 \mu \mathrm{g} / \mathrm{mL})$ efficiently inhibited the biofilm biomass growth of some uropathogens, including Escherichia coli (52\%), Pseudomonas aeruginosa PAO1 (89\%), Proteus mirabilis (52\%) and Serratia marcescens (76\%). In addition, the combined effects of curcumin and honey, as a traditional medicine, and epigallocatechin gallate, as a green tea polyphenol, were reported to enhance significantly the inhibition of biofilm formation in wastewater bacteria (52 to $99 \%$ ) and $P$. aeruginosa PAO1 (20 to $94.6 \%$ ) $(21,42)$. Therefore, the antibiofilm activity of curcumin may vary depending on the type of strain, the method used and/or its combination with some other constituent. Our results (Fig. 3) showed that although curcumin exhibited a weak biofilm inhibition potential at concentrations of 46.87 and $93.75 \mu \mathrm{g} / \mathrm{mL}$, at higher sub-MICs of $187.5,375$ and $750 \mu \mathrm{g} / \mathrm{mL}$, it had a strong concentrationdependent activity ((57.7 \pm 0.4$),(75.6 \pm 1.0)$ and $(84.2 \pm 0.2) \%$; $p<0.05)$. Fig. 3 shows that the biofilm inhibitory potentials of the phytochemicals at concentrations of 46.87 and $93.75 \mu \mathrm{g} /$ $\mathrm{mL}$ increased in the following order: gallic acid<curcumin< pyrogallol<quercetin<apigenin<luteolin. At these concentrations, luteolin had the maximum biofilm inhibition values of $(46.94 \pm 0.05)$ and $(60.0 \pm 0.2) \%$, respectively. Quercetin, apigenin and pyrogallol also significantly reduced $(p<0.05)$ the biofilm formation of C. violaceum 12472 (Fig. 3).

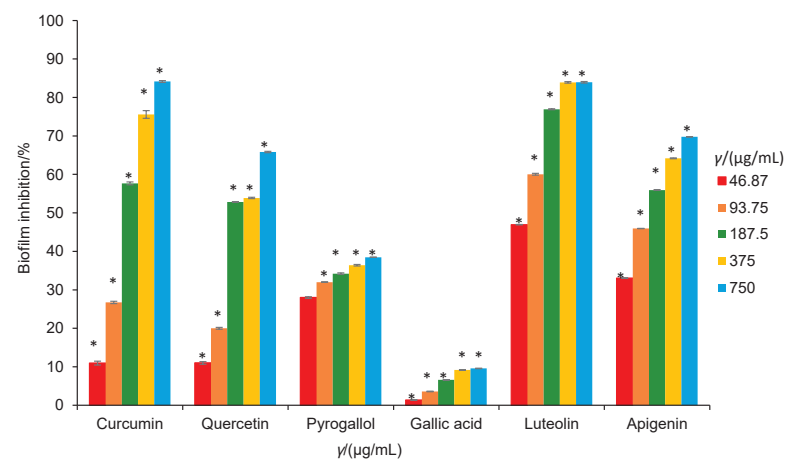

Fig. 3. The percentage of biofilm inhibition in Chromobacterium violaceum ATCC 12472 by the dietary phytochemicals at the subminimal inhibitory concentrations $(46.87-750 \mu \mathrm{g} / \mathrm{mL})$. Data are presented as a percentage of violacein inhibition. Mean values of triplicate independent experiments and S.D. are shown. The control groups were: $0.5 \%$ DMSO, $0.5 \%$ methanol and the bacteria cultured in Luria-Bertani broth. *Statistically different from the control $(p<0.05)$

Pyrogallol showed weak biofilm inhibition with (34.2 \pm 0.2$)$, $(36.4 \pm 0.2)$ and $(38.5 \pm 0.0) \%$ at higher sub-MICs of 187.5 , 375 and $750 \mu \mathrm{g} / \mathrm{mL}$, respectively (Fig. 3). Thus, the biofilm inhibitory potentials of all the phytochemicals at higher subMICs of 187.5 and $375 \mu \mathrm{g} / \mathrm{mL}$ increased in the following order: gallic acid<pyrogallol<quercetin<apigenin<curcumin<luteolin. Luteolin had the maximum biofilm inhibition $((46.94 \pm 0.05)-(83.9 \pm 0.2) \%)$ at the sub-MIC values of 46.87 to $375 \mu \mathrm{g} / \mathrm{mL}$. Our results are in accordance with the findings of Vikram et al. (43), who reported that quercetin and apigenin reduced the biofilm formation in $V$. harveyi and $E$. 
coli 0157:H7. In addition, Shehzad et al. (44) and Lee et al. (45) also reported that curcumin, pyrogallol and apigenin were effective polyphenols against the biofilm formation of Candida albicans.

\section{Swimming and swarming motility}

In this study, the motility (swimming and swarming behaviour) of $P$. aeruginosa PAO1 in the presence and absence of the dietary phytochemicals at the sub-MIC of $93.75 \mu \mathrm{g} /$ $\mathrm{mL}$ was evaluated using agar plates. Our results demonstrate that all the phytochemicals significantly $(p<0.05)$ blocked the swimming and swarming motility of $P$. aeruginosa PAO1 without impairing its growth capacity. Its swimming and swarming motilities after the treatment with the phytochemicals were observed to be significantly poor ( $<<0.05$; Table 2 ). Compared to the control, curcumin exhibited the maximum reduction in the swimming and swarming motility assays. These results are in accordance with the previous reports of Packiavathy et al. (19) and Jadaun et al. (42), who observed a remarkable decrease in the swimming and swarming motility of $P$. aeruginosa PAO1 when treated with curcumin. Table 2 also indicates the inhibition of swimming and swarming behaviour of $P$. aeruginosa PAO1 by quercetin.

Table 2. Effect of the dietary phytochemicals at the subminimal inhibitory concentration $(93.75 \mu \mathrm{g} / \mathrm{mL})$ on swimming and swarming motility of Pseudomonas aeruginosa PAO1

\begin{tabular}{ccc} 
Phytochemical & \multicolumn{2}{c}{$/($ migration $) / \mathrm{mm}$} \\
\cline { 2 - 3 } Control & $(44.0 \pm 3.5)^{\mathrm{a}}$ & $(32.0 \pm 1.7)^{\mathrm{a}}$ \\
CR & $(11.3 \pm 0.4)^{\mathrm{b}^{*}}$ & $(12.5 \pm 0.7)^{\mathrm{b}^{*}}$ \\
QT & $(15.7 \pm 0.6)^{\mathrm{c}^{*}}$ & $(14.5 \pm 0.7)^{\mathrm{c}^{*}}$ \\
PG & $(19.3 \pm 1.2)^{\mathrm{d}^{*}}$ & $(16.0 \pm 1.4)^{\mathrm{d}^{*}}$ \\
GA & $(33.3 \pm 0.6)^{\mathrm{e}^{*}}$ & $\left(25.5 \pm 2.1 \mathrm{e}^{\mathrm{e}^{*}}\right.$ \\
LT & $(28.6 \pm 0.4)^{\mathrm{f}^{*}}$ & $(23.5 \pm 1.3)^{\mathrm{f}^{*}}$ \\
AP & $(26.4 \pm 0.5)^{\mathrm{g}^{*}}$ & $(17.5 \pm 0.4)^{\mathrm{g}^{*}}$
\end{tabular}

$\mathrm{CR}=$ curcumin, $\mathrm{QT}=$ quercetin, $\mathrm{PG}=$ pyrogallol, $\mathrm{GA}=$ gallic acid, $\mathrm{LT}=$ luteolin, $\mathrm{AP}=$ apigenin. The data represent the mean values of three independent experiments. The values in the same column with different letters in superscript are significantly different $(p<0.05)$ *Statistically different from the control $(p<0.05)$

Our findings are consistent with the reports of Vasavi et al. (20), who found that the flavonoid fraction of Psidium guajava leaves included an active compound, quercetin-3-O-arabinoside, inhibits the swarming motility of $P$. aeruginosa PAO1. In addition, Gopu et al. (6) reported that quercetin significantly reduced the swimming and swarming behaviour of foodborne isolates of Pseudomonas aeruginosa PUFSTb04 at the concentration of $80 \mu \mathrm{g} / \mathrm{mL}$. Table 2 shows that the inhibition potential of the swimming and swarming motilities of the bacterial strain by the investigated phytochemicals decreased in the following order: curcumin $>$ quercetin $>$ pyrogallol>apigenin>luteolin> gallic acid.

The obtained results clearly indicate that curcumin and quercetin exhibited the most powerful inhibition of the motility. The results also suggest a correlation between the inhibition of the swimming and swarming motility for each phytochemical.

\section{Bacterial growth curve}

The bacterial growth curve revealed that the sub-MIC concentrations of dietary phytochemicals used in this study ( 375 and $750 \mu \mathrm{g} / \mathrm{mL}$ ) did not have a growth inhibitory effect on C. violaceum 12472 (Fig. S1).

\section{CONCLUSIONS}

This study investigated the inhibitory potentials of six dietary phytochemicals (curcumin, quercetin, apigenin, luteolin, gallic acid and pyrogallol) against the violacein pigment production that is controlled by quorum sensing (QS) and biofilm formation in Chromobacterium violaceum ATCC 12472 biosensor system, and their impact on swimming and swarming behaviour of Pseudomonas aeruginosa PAO1. Our results also demonstrated that all the phytochemicals, except pyrogallol and gallic acid, inhibited the violacein production. Moreover, the biofilm formation was significantly hindered by all the phytochemicals at each of the sub-MICs in the range of $46.87-750 \mu \mathrm{g} / \mathrm{mL}(\mathrm{p}<0.05)$. Although some of the phytochemicals, especially curcumin and quercetin, possess QS and biofilm inhibitory potentials, this study reveals that apigenin and luteolin could also inhibit QS and biofilm formation. Our results also show that all the phytochemicals, especially curcumin, quercetin and pyrogallol, may be used as anti-pathogenic agents, particularly against $P$. aeruginosa PAO1, owing to QS control; however, more detailed experiments should be performed to find out their anti-QS mechanisms. Since these phytochemicals are the active compounds in foods such as onion, broccoli, apples, avocado, mango, banana, parsley, cabbage, carrots, mustard, pepper and radish, the consumption of these foods might be beneficial in the treatment of bacterial infections. In addition, the studies of QS inhibitory potentials of the phytochemicals, especially apigenin and luteolin, against other biosensor strains, and the antibiofilm effect of the phytochemicals against different pathogens are scarce in the literature. Therefore, we suggest that more detailed experiments be conducted to reveal the anti-QS mechanisms and the pharmaceutical potential of the phytochemicals used in this study to confirm these results at the molecular level.

\section{FUNDING}

This work was supported by the Scientific Research Projects Unit of Gazi University of Turkey (grant number 21/2015-01).

\section{CONFLICT OF INTEREST}

The authors declare that there are no conflicts of interest.

\section{SUPPLEMENTARY MATERIAL}

All supplementary material is available at www.ftb.com.hr. 


\section{ORCID IDs}

E.B. Bali (1) https://orcid.org/0000-0002-8797-0573

K. Erkan Türkmen (1) https://orcid.org/0000-0002-4813-7941

D. Erdönmez (iD https://orcid.org/0000-0003-3955-1734

N. Sağlam (10) https://orcid.org/0000-0002-5463-8355

\section{REFERENCES}

1. Meher-Homji Z, Mangalore RP, Johnson PDR, Chua KY. Chromobacterium violaceum infection in chronic granulomatous disease: A case report and review of the literature. JMM Case Rep. 2017;4(1).

https://doi.org/10.1099/jmmcr.0.005084

2. Richard KR, Lovvorn JJ, Oliver SE, Ross SA, Benner KW, Kong MYF. Chromobacterium violaceum sepsis: Rethinking conventional therapy to improve outcome. Am J Case Rep. 2015;16:740-4.

https://doi.org/10.12659/AJCR.894509

3. Morohoshi T, Kato M, Fukamachi K, Kato N, Ikeda T. N-acylhomoserine lactone regulates violacein production in Chromobacterium violaceum type strain ATCC 12472. FEMS Microbiol Lett. 2008;279(1):124-30.

https://doi.org/10.1111/j.1574-6968.2007.01016.x

4. Stauff DL, Bassler BL. Quorum sensing in Chromobacterium violaceum: DNA recognition and gene regulation by the CviR receptor. J Bacteriol. 2011;193(15):3871-8. https://doi.org/10.1128/JB.05125-11

5. Zhu H, He CC, Chu QH. Inhibition of quorum sensing in Chromobacterium violaceum by pigments extracted from Auricularia auricular. Lett Appl Microbiol. 2011;52(3):269-74. https://doi.org/10.1111/j.1472-765X.2010.02993.x

6. Gopu V, Meena CK, Shetty PH. Quercetin influences quorum sensing in food borne bacteria: in-vitro and in-silico evidence. PLoS One. 2015;10(8):e0134684.

https://doi.org/10.1371/journal.pone.0134684

7. Bai AJ, Vittal RR. Quorum sensing inhibitory and anti-biofilm activity of essential oils and their in vivo efficacy in food systems. Food Biotechnol. 2014;28(3):269-92.

https://doi.org/10.1080/08905436.2014.932287

8. Husain FM, Ahmad I, Khan MS, Ahmad E, Tahseen Q, Khan MS, Alshabib NA. Sub-MICs of Mentha piperita essential oil and menthol inhibits AHL mediated quorum sensing and biofilm of Gram-negative bacteria. Front Microbiol. 2015;6: Article No.420.

https://doi.org/10.3389/fmicb.2015.00420

9. Overhage J, Lewenza S, Marr AK, Hancock REW. Identification of genes involved in swarming motility using a Pseudomonas aeruginosa PAO1 mini-Tn5-lux mutant library. J Bacteriol. 2007;189(5):2164-9.

https://doi.org/10.1128/JB.01623-06

10. Chow S, Gu K, Jiang L, Nassour A. Salicylic acid affects swimming, twitching and swarming motility in Pseudomonas aeruginosa, resulting in decreased biofilm formation. J Experim Microbiol Immunol. 2011;15:22-9.

11. Alayande AB, Aung MM, Kim IS. Correlation between quorum sensing signal molecules and Pseudomonas aeruginosa's biofilm development and virulency. Curr Microbiol. 2018;75(7):787-93.

https://doi.org/10.1007/s00284-018-1449-5

12. Borges A, Serra S, Abreu AC, Saavedra MJ, Salgado A, Simões $M$. Evaluation of the effects of selected phytochemicals on quorum sensing inhibition and in vitro cytotoxicity. Biofouling. 2014;30(2):183-95.

https://doi.org/10.1080/08927014.2013.852542

13. Akkoç N, Akçelik M, Haznedaroglu IC, Goker H, Turgut M, Aksu S, et al. In vitro anti-bacterial activities of Ankaferd medicinal plant extract. Turkiye Klinikleri J Med Sci. 2009; 29(2): 410-5.

14. Reen FJ, Gutiérrez-Barranquero JA, Parages ML, O'Gara F. Coumarin: A novel player in microbial quorum sensing and biofilm formation inhibition. Appl Microbiol Biotechnol. 2018;102(5):2063-73.

https://doi.org/10.1007/s00253-018-8787-x

15. Husain FM, Ahmad I, Al-thubiani AS, Abulreesh HH, AlHazza IM, Aqil F. Leaf extracts of Mangifera indica L. inhibit quorum sensing-regulated production of virulence factors and biofilm in test bacteria. Front Microbiol. 2017;8:Article no. 727. https://doi.org/10.3389/fmicb.2017.00727

16. Rajkumari J, Borkotoky S, Murali A, Suchiang K, Mohanty SK, Busi S. Attenuation of quorum sensing controlled virulence factors and biofilm formation in Pseudomonas aeruginosa by pentacyclic triterpenes, betulin and betulinic acid. Microb Pathog. 2018;118:48-60.

https://doi.org/10.1016/j.micpath.2018.03.012

17. Zhou JW, Luo HZ, Jiang H, Jian TK, Chen ZQ, Jia AQ. Hordenine, a novel quorum sensing inhibitor and antibiofilm agent against Pseudomonas aeruginosa. J Agric Food Chem. 2018;66(7):1620-8.

https://doi.org/10.1021/acs.jafc.7b05035

18. Packiavathy IASV, Sasikumar P, Pandian SK, Ravi AV. Prevention of quorum-sensing-mediated biofilm development and virulence factors production in Vibrio spp. by curcumin. Appl Microbiol Biotechnol. 2013;97(23):10177-87. https://doi.org/10.1007/s00253-013-4704-5

19. Packiavathy IASV, Priya S, Pandian SK, Ravi AV. Inhibition of biofilm development of uropathogens by curcumin An anti-quorum sensing agent from Curcuma longa. Food Chem. 2014;148:453-60. https://doi.org/10.1016/j.foodchem.2012.08.002

20. Vasavi HS, Arun AB, Rekha PD. Anti-quorum sensing activity of Psidium guajava L. flavonoids against Chromobacterium violaceum and Pseudomonas aeruginosa PAO1. Microbiol Immunol. 2014;58(5):286-93.

https://doi.org/10.1111/1348-0421.12150 
21. Lade H, Paul D, Kweon JH. Combined effects of curcumin and (-)-epigallocatechin gallate on inhibition of $\mathrm{N}$-acylhomoserine lactone-mediated biofilm formation in wastewater bacteria from membrane bioreactor. J Microbiol Biotechnol. 2015;25(11):1908-19.

https://doi.org/10.4014/jmb.1506.06010

22. Zgoda J, Porter J. A convenient microdilution method for screening natural products against bacteria and fungi. Pharm Biol. 2001;39(3):221-5.

https://doi.org/10.1076/phbi.39.3.221.5934

23. Bauer AW, Kirby WMM, Sherris JC, Turck M. Antibiotic susceptibility testing by a standardized single disk method. Am J Clin Pathol. 1966;45(4):493-6. https://doi.org/10.1093/ajcp/45.4_ts.493

24. Blosser RS, Gray KM. Extraction of violacein from Chromobacterium violaceum provides a new quantitative bioassay for $\mathrm{N}$-acyl homoserine lactone autoinducers. J Microbiol Methods. 2000;40(1):47-55.

https://doi.org/10.1016/S0167-7012(99)00136-0

25. O'Toole GA, Kolter R. Initiation of biofilm formation in Pseudomonas fluorescens WCS365 proceeds via multiple, convergent signalling pathways: A genetic analysis. Mol Microbiol. 1998;28(3):449-61.

https://doi.org/10.1046/j.1365-2958.1998.00797.x

26. Packiavathy IASV, Agilandeswari P, Musthafa KS, Pandian SK, Ravi AV. Antibiofilm and quorum sensing inhibitory potential of Cuminum cyminum and its secondary metabolite methyl eugenol against Gram negative bacterial pathogens. Food Res Int. 2012;45(1):85-92.

https://doi.org/10.1016/j.foodres.2011.10.022

27. SPSS software, v. 20, IBM Corporation, Armonk, NY, USA; 2011. Available from: https://www.ibm.com/analytics/ spss-statistics-software.

28. Borges A, Ferreira C, Saavedra MJ, Simões M. Antibacterial activity and mode of action of ferulic and gallic acids against pathogenic bacteria. Microb Drug Resist. 2013;19(4):256-65. https://doi.org/10.1089/mdr.2012.0244

29. Silva V, Igrejas G, Falco V, Santos TP, Torres C, Oliveira AMP, et al. Chemical composition, antioxidant and antimicrobial activity of phenolic compounds extracted from wine industry by-products. Food Control. 2018;92:516-22. https://doi.org/10.1016/j.foodcont.2018.05.031

30. Gutiérrez-del-Río I, Fernández J, Lombó F. Plant nutraceuticals as antimicrobial agents in food preservation: Terpenoids, polyphenols and thiols. Int J Antimicrob Agents. 2018;52(3):309-15.

https://doi.org/10.1016/j.jjantimicag.2018.04.024

31. Ohemeng KA, Schwender CF, Fu KP, Barrett JF. DNA gyrase inhibitory and antibacterial activity of some flavones (1). Bioorg Med Chem Lett. 1993;3(2):225-30. https://doi.org/10.1016/S0960-894X(01)80881-7

32. Mirzoeva OK, Grishanin RN, Calder PC. Antimicrobial action of propolis and some of its components: The effects on growth, membrane potential and motility of bacteria. Microbiol Res. 1997;152(3):239-46.

https://doi.org/10.1016/S0944-5013(97)80034-1

33. Sorrentino E, Succi M, Tipaldi L, Pannella G, Maiuro L, Sturchio $M$, et al. Antimicrobial activity of gallic acid against food-related Pseudomonas strains and its use as biocontrol tool to improve the shelf life of fresh black truffles. Int J Food Microbiol. 2018;266:183-9.

https://doi.org/10.1016/j.ijfoodmicro.2017.11.026

34. Al-Hussaini R, Mahasneh AM. Microbial growth and quorum sensing antagonist activities of herbal plants extracts. Molecules. 2009;14(9):3425-35.

https://doi.org/10.3390/molecules14093425

35. Brackman G, Hillaert U, Van Calenbergh S, Nelis HJ, Coenye T. Use of quorum sensing inhibitors to interfere with biofilm formation and development in Burkholderia multivorans and Burkholderia cenocepacia. Res Microbiol. 2009;160(2): 144-51.

https://doi.org/10.1016/j.resmic.2008.12.003

36. Vandeputte OM, Kiendrebeogo M, Rasamiravaka T, Stévigny C, Duez P, Rajaonson S, et al. The flavanone naringenin reduces the production of quorum sensing-controlled virulence factors in Pseudomonas aeruginosa PAO1. Microbiology. 2011;157(Part 7):2120-32.

https://doi.org/10.1099/mic.0.049338-0

37. Borges A, Ferreira C, Saavedra MJ, Simões M. Antibacterial activity and mode of action of ferulic and gallic acids against pathogenic bacteria. Microb Drug Resist. 2013;19(4):256-65. https://doi.org/10.1089/mdr.2012.0244

38. Tinh TH, Nuidate T, Vuddhakul V, Rodkhum C. Antibacterial activity of pyrogallol, a polyphenol compound against $\mathrm{Vi-}$ brio parahaemolyticus isolated from the central region of thailand. Procedia Chem. 2016;18:162-8.

https://doi.org/10.1016/j.proche.2016.01.025

39. Ni N, Choudhary G, Li M, Wang B. Pyrogallol and its analogs can antagonize bacterial quorum sensing in Vibrio harveyi. Bioorg Med Chem Lett. 2008;18(5):1567-72.

https://doi.org/10.1016/j.bmcl.2008.01.081

40. Nazzaro F, Fratianni F, Coppola R. Quorum sensing and phytochemicals. Int J Mol Sci. 2013;14(6):12607-19.

https://doi.org/10.3390/ijms140612607

41. Defoirdt T, Pande GSJ, Baruah K, Bossier P. The apparent quorum-sensing inhibitory activity of pyrogallol is a side effect of peroxide production. Antimicrob Agents Chemother. 2013;57(6):2870-3.

http://doi.org/10.1128/AAC.00401-13

42. Jadaun V, Prateeksha, Singh BR, Paliya BS, Upreti DK, Rao $\mathrm{CV}$, et al. Honey enhances the anti-quorum sensing activity and anti-biofilm potential of curcumin. RSC Adv. 2015;5(87): 71060-70.

https://doi.org/10.1039/C5RA14427B 
43. Vikram A, Jayaprakasha GK, Jesudhasan PR, Pillai SD, Patil BS. Suppression of bacterial cell-cell signalling, biofilm formation and type III secretion system by citrus flavonoids. J Appl Microbiol. 2010;109(2):515-27. https://doi.org/10.1111/j.1365-2672.2010.04677.x

44. Shehzad A, Shahzad R, Lee YS. Curcumin: A potent modulator of multiple enzymes in multiple cancers.
Enzymes. 2014; 36:149-74.

https://doi.org/10.1016/B978-0-12-802215-3.00008-2

45. Lee $H$, Woo ER, Lee DG. Apigenin induces cell shrinkage in Candida albicans by membrane perturbation. FEMS Yeast Res. 2018;18(1):foy003.

https://doi.org/10.1093/femsyr/foy003 